Estudios Fronterizos, vol. 10, núm. 19, enero-junio 2009, pp. 49-83

\title{
Análisis regional de las remesas y sus perceptores en México, 2000 y 2005
}

\author{
Luis Huesca Reynoso* \\ Cuauhtémoc Calderón Villarreal** \\ Jazmín García Gómez ${ }^{* * *}$
}

Resumen. Este trabajo analiza la estructura de los perfiles que mantienen los perceptores de las remesas en México. Se realiza un estudio micro-econométrico de los factores individuales que nos permiten comprender la conducta y el perfil de los perceptores de la remesas en los hogares y en las regiones de México. Para ello, utilizamos la Encuesta Nacional de Ingresos y Gastos de los Hogares (ENIGH) de los años 2000 y 2005. La hipótesis central de este trabajo es que la experiencia y las habilidades de los migrantes con el capital social de su entorno presentan comportamientos diferenciados entre los perceptores de remesas ubicados en distintas regiones mexicanas.

Palabras clave: análisis bayesiano, migración, remesas, capital social, modelos de elección.

Abstract. This paper analyzes the profile's structure kept by earners of remittances in Mexico. A micro-econometric study of the individual factors is carried out in order to understand both, the behavior and the profile of them for households and regions in Mexico. In doing so, we use the 2000 and 2005 National surveys of household income and expenditure (-ENIGH- for its acronym in Spanish). The hypothesis guiding this research is that experience and skills of emigrants with their social capital endowments outline a different pattern between the earners of remittances located at distinct Mexican regions.

Keywords: bayesian analysis, migration, remittances, social capital, choice models.

* Investigador titular del Centro de Investigación en Alimentación y Desarrollo, A.C. Correo electrónico: lhuesca@ciad.mx

** Investigador titular de El Colegio de la Frontera Norte. Correo electrónico: calderon@colef.mx

*** Estudiante de la maestría en Desarrollo Regional del Centro de Investigación en Alimentación y Desarrollo, A.C. Correo electrónico: jazgago@yahoo.com.mx 


\section{Introducción}

La emigración masiva de mexicanos hacia los Estados Unidos de América se ha convertido en uno de los hechos estilizados más característicos de la economía mexicana en la década de los noventa. Este flujo masivo de migrantes ha ido creciendo y es el resultado de las asimetrías económicas estructurales que se dieron a partir de la apertura económica total de México a raíz de la firma del Tratado de Libre Comercio de Norte América (TLCAN) (Calderón, 2006).

Este proceso ha fortalecido la presencia, en los Estados Unidos, de una población de migrantes de origen mexicano que mantiene costumbres y valores culturales muy diferentes de aquellos en la población nativa de los Estados Unidos. Además de la formación de redes sociales de migración tanto en el país receptor (Estados Unidos) como en el país expulsor (México). Estas redes sociales, o capital social, son el resultado de los lazos familiares y de grupos de trabajadores que se han ido tejiendo a lo largo de esta década. Por el lado del país expulsor, o sea México, la red social se convirtió en el vehículo por medio del cual el ingreso proveniente de la remesas no sólo amplió el consumo, sino que también ha sido un medio por el cual los miembros de esta red social adoptan una actitud más emprendedora, con efectos económicos positivos limitados al espacio local.

Por lo anterior, el impacto económico local de las remesas tenderá a ser mayor en aquellas entidades del país, o regiones, con mayor concentración absoluta y relativa de emigrantes internacionales. Para la teoría económica estándar, la migración internacional es un "proceso natural" por medio del cual los individuos migrantes se desplazan a otro país para mejorar su nivel de bienestar. Así, las variables claves explicativas de este proceso serían la búsqueda de un mejor empleo y un mejor nivel salarial. Sin embargo, existen otros aspectos que no están presentes en la teoría económica tradicional de la migración internacional, como son el costo de la migración, la actitud frente al riesgo, la hipótesis de privación relativa y el papel del capital social o redes sociales, que son tomados en cuenta por la Nueva Economía de la Migración Laboral -NELM, por sus siglas en inglés- (Stark y Bloom, 1985, y Stark, 2000). 
El presente trabajo se sitúa en esta perspectiva analítica y de manera particular pretende analizar el efecto que ha tenido la formación de las redes sociales de los trabajadores migrantes en el país expulsor, México, sobre la distribución y el gasto local de las remesas que llegan de los Estados Unidos. Desde nuestra perspectiva, estas redes sociales respaldan todo un proceso iterativo que incorpora no solamente la decisión del jefe del hogar, sino también actitudes basadas en la toma de decisiones en el seno familiar, en función de las habilidades y aptitudes que tenga cada miembro.

El objetivo de este documento reside en hacer un comparativo entre los años 2000 y 2005 analizando la estructura de los perfiles que mantienen los perceptores de las remesas, para lo cual se realizó un estudio micro-econométrico de los factores que permitan comprender la conducta y el perfil de los perceptores de la remesas en los hogares a nivel regional. En esto radica la novedad de este trabajo, ya que la mayor parte de los estudios realizados a la fecha -en nuestro conocimiento- se refieren al análisis del fenómeno desde una perspectiva exclusivamente macroeconómica.

Partimos del enfoque de la NELM, según el cual el fortalecimiento de las redes sociales de migrantes con lazos familiares y de su propio entorno del lugar de origen provoca que las decisiones en el hogar adquieran una relevancia asociada a las aptitudes de cada miembro perceptor.

El trabajo presenta el siguiente orden. En la primera parte, se describen los enfoques teóricos y la evidencia reciente sobre la teoría NELM; la segunda describe la metodología y el modelo a emplear; el tercer y cuarto apartados muestran la aplicación empírica de la investigación y la conclusión del documento respectivamente.

\section{Enfoques teóricos y evidencia de la NELM}

Hoy en día, se observa a la migración como una alternativa de trabajo, que no sólo permite salir de la pobreza a una gran cantidad de individuos y hogares, sino también de prepararse, logrando mayores capacidades y experiencia laboral, que seguramente aplicarán al retorno del lugar de origen (Meza et al., 2006). Originalmente se pensa- 
ba que la migración interna acelerada era un proceso deseable por el cual el excedente de la fuerza de trabajo, en los sectores rurales, podía ser trasladado a los sectores modernos y acelerar el crecimiento económico (Todaro, 1995). Implícita en las hipótesis de los pioneros de la disciplina de la economía del desarrollo (Lewis, 1954, Fei y Ranis, 1961), la migración interna facilitaría el traslado de recursos humanos desde áreas donde la productividad marginal del trabajo era nula, hacia zonas donde ésta prácticamente era creciente.

Harris y Todaro (1970) elaboran un modelo de comercio interno de dos sectores (urbano y rural) de migración y desempleo, suponiendo desde entonces, que el migrante promedio mantiene sus lazos con el sector rural. Por su parte, Fields (1975) extendió el modelo previo, incorporando la posibilidad de que un residente rural encuentre trabajo en el sector urbano antes de emigrar, e incorpora la posibilidad de que la educación sea utilizada como mecanismo de selección en el mercado de trabajo urbano, y así otorgarles mejores posibilidades a los trabajadores rurales más educados. Por ello es importante definir aquí al actor principal, el emigrante y perceptor, que aun siendo la misma persona, comparte el fruto de su esfuerzo con la familia.

Sin embargo, el modelo clásico de Harris y Todaro (1970) no toma en cuenta aspectos como el costo de migración, la actitud frente al riesgo, la hipótesis de privación relativa y el papel del capital social. Dichos aspectos explicativos de la migración son desarrollados por la NELM, la cual proviene del concepto de la nueva economía política (new political economy) de la economía de la familia que analiza los incentivos y las implicaciones de las decisiones tomadas por los miembros de la familia, en el sentido de maximizar sus ganancias en la búsqueda de mejores alternativas de trabajo (Stark y Bloom, 1985, y Stark, 2000).

De acuerdo con el enfoque de la NELM, las variables que aproximan la hipótesis son aquellas relacionadas con el acervo de bienes (físicos e intangibles por las remesas) en la familia que impactan en la toma de decisiones al interior del hogar. En este estudio las aproximamos con el tamaño del hogar, la presencia de niños, si la casa habitada es propia y que la misma tenga algunos satisfactores como teléfono y enseres domésticos, además de que el perceptor de las remesas tenga 
un automóvil para trabajo. En el Anexo desagregamos las variables que componen la NELM en el Cuadro A1 y su estadística descriptiva básica en el Cuadro A3.

En los años ochenta el sociólogo francés Pierre Bourdieu definió al capital social como "el conjunto de recursos actuales o potenciales que están ligados a la posesión de una red durable de relaciones más o menos institucionalizadas de conocimiento y reconocimiento mutuo o [...] de pertenencia a un grupo" (Bourdieu, 1980:2).

De acuerdo con algunos de los autores de la NELM, ${ }^{1}$ el capital social o la red social puede influir sobre el flujo migratorio y, recíprocamente, la migración tener un efecto sobre el capital social. Según Schiff (1999a, 1999b y 2002), existe una diferencia sustancial entre el libre comercio y la libre migración dado que esta última afecta al capital social. La migración tiene un efecto sobre el capital social del país de emigración como del país de inmigración. En el país expulsor, el capital social decrece con el nivel de migración como consecuencia de la reducción del tamaño de la red social o de los colectivos con los cuales comparten valores e interactúan. En el país receptor el capital social depende negativamente de la migración, ya que la migración afecta la capacidad de los miembros de la sociedad para compartir los mismos valores, comunicarse y poder actuar en común.

Como parte de esta corriente, el trabajo pionero de Stark y Bloom (1985) indica que la migración es una manera de mitigar el impacto de las fallas en los mercados de seguros, de capitales y de crédito de los países menos desarrollados (Stark y Bloom, 1985, Sana y Massey, 2005, y Meza et al., 2006). Desde la perspectiva de estos autores, se envía a un miembro de la familia para que trabaje en el extranjero. De modo que la familia hace una inversión inicial enviándolo afuera del país y espera recuperarla en un futuro, cuando vuelva en forma de remesas. En este caso, se considera un arreglo contractual implícito o explícito entre la familia y el emigrante (Stark y Lucas, 1988).

Por su parte, Carriles et al. (1991) y Tuirán (2001) indican que uno de los impactos económicos de mayor influencia de la migración in-

\footnotetext{
${ }^{1}$ Al respecto podemos citar a Stark y Bloom (1985), Stark y Lucas (1988), Stark y Wang (2000), y Shiff (1999 y 2002).
} 
ternacional es la cantidad de dinero que remiten estos trabajadores a sus familias en México. Se asume que ambos son familiares y que el envío tiene por objeto contribuir en la manutención familiar. Es en este entorno en el que desarrolla el documento: las remesas familiares y sus perceptores.

La mayor parte de los estudios sobre el tema se han enfocado a aspectos macroeconómicos (Carriles et al., 1991, Zárate-Hoyos, 2004, Muñoz, 2006a y 2006b, Calderón y Mendoza, 2005 y 2006, y Calderón y Hernández, 2007). De la reducida evidencia existente a la fecha -en nuestro conocimiento- que considera de alguna manera la hipótesis de la NELM, se puede contar con los trabajos de Stark, Taylor y Yitzhaki (1986), Taylor y Martin (2001), Stark y Quiang-Wang (2000), Brauw et al. (2001), Aguirre e Infante (2005), Meza et al. (2006), Chávez (2006a, 2006b) y Quinn (2006). Estos estudios analizan las remesas y la migración con enfoques que van desde el bienestar que producen en la distribución (Stark et al., 1986) hasta sus vínculos con el capital humano (Taylor y Martin, 2001, y Quinn, 2006) y el desarrollo productivo en la generación de microempresas (Woodruff y Zenteno, 2001, Aguirre e Infante, 2005, y Meza et al., 2006). ${ }^{2}$

Por ejemplo, Quinn (2006) observa que las políticas públicas de inversión focalizadas erróneamente, en lugar de disminuir la emigración provocan un incremento, y los individuos relativamente privados ven su situación con nivel inferior al estándar de la comunidad. En relación con la edad, este autor muestra que los migrantes hacia Estados Unidos son más jóvenes que los migrantes internos, con un promedio de 32.5 años contra 42.6 años respectivamente; mientras que la educación indica una relación negativa con respecto de la migración hacia EE. UU. y una relación positiva con la migración interna. Asimismo, observa la existencia de una relación positiva entre las variables de la privación relativa con la migración hacia EE. UU., así como también al interior de México.

\footnotetext{
${ }^{2}$ El estudio de Meza et al. (2006) prueba estadísticamente que la inversión de las remesas en microempresas sería otra manera por la cual las familias verían recompensada su inversión en el financiamiento del viaje migratorio.
} 


\section{Metodología y modelo}

La mayor parte de los estudios aplicados en este tema han empleado funciones de migración agregadas que generalizan el fenómeno, lo que ha impedido probar hipótesis a escala individual y con características que capturen la influencia que presentan variables explicativas alternas a la problemática en cuestión. Lo anterior ha causado inferencias erróneas e interpretaciones ambiguas con las respectivas limitantes (Taylor y Martin, 2001). En la última década, gracias al acceso a bases de datos desagregadas en México, y al uso de microdatos, con la aplicación de modelos de tipo Multinomial Logit y de máxima verosimilitud, es factible probar hipótesis con mayor nivel de desagregación; por ello este trabajo se enfoca a utilizar la estimación paramétrica de un modelo multinomial de respuesta discreta, que permitirá desagregar los impactos y la influencia de cada característica sobre la probabilidad de ocurrencia de las remesas en sus perceptores.

El modelo a aplicar sigue la forma de una ecuación de regresión con respuesta discreta, donde la variable dependiente toma el conjunto de $n$ atributos a ser explicados dentro de las alternativas $j=1, \ldots . n$ de la siguiente forma:

$$
M_{j}=\eta_{0}+\eta_{1} Z_{j}^{\prime}+\eta_{2} X_{j}^{\prime}+\varepsilon_{j}
$$

donde $M$ es la variable dependiente, que indica el conjunto de alternativas $j$ de respuesta para el individuo, el término constante es $\eta_{\mathrm{o}}$, el vector de características individuales y del hogar que afectan las alternativas son $Z_{j}$ y $X_{j}$ y el término de error que cumple con las condiciones habituales de normalidad es $\varepsilon_{j}$.

Los estimadores $\left(\eta_{j}\right)$ se obtienen a través del proceso de máxima verosimilitud. La expresión (2) representa la probabilidad de que un individuo con atributos $z_{j}$ y $x_{j}$ seleccione el segmento -regional o de posición en el trabajo $j$ en nuestro caso-, asumiendo que toda la muestra se refiere solamente a personas con percepciones de remesas, y por tanto, con individuos emigrantes.

Las probabilidades se han obtenido a través de la siguiente expresión: 


$$
\operatorname{Pr}=(y=m \mid z, x)=\frac{\exp \left(z, x \hat{\eta}_{m \mid J}\right)}{\sum_{j=1}^{J} \exp \left(z, x \hat{\eta}_{j \mid J}\right)}
$$

donde $m$ es la variable dependiente con respuesta $(1, \ldots, n), z$ y $x$ son los valores medios de los atributos de los individuos, y los $\hat{\eta}$ son los coeficientes de la regresión multinomial para cada respuesta $m$ con $J$ alternativas. El último paso es el cálculo de los cambios de probabilidad, mejor conocidos como efectos marginales o cambios discretos, y se calculan con la fórmula que se muestra a continuación:

$$
\frac{\Delta y}{\Delta d}=\left(\eta_{0}+z^{\prime}{ }_{j} \eta_{1}+x^{\prime}{ }_{j} \eta_{2}+\delta 1\right)-\left(\eta_{0}+z_{j}^{\prime} \eta+x^{\prime}{ }_{j} \eta_{2}+\delta 0\right)=\delta
$$

El cambio discreto en las probabilidades no es lineal, porque el efecto de un cambio en una variable dependerá de los valores medios del resto de ellas en el modelo, y no será constante al que resulte de los parámetros estimados por el modelo. Por ello, para cada categoría y atributo empleados, la ecuación (3) se resume en un cambio discreto cada vez distinto, al pasar de los valores de 0 a 1 en la variable discreta de referencia, y manteniendo constante las medias del resto de variables independientes, como se indica en la expresión (4):

$$
\frac{\Delta \operatorname{Pr}(y=0)}{\Delta d} \neq \delta \neq \frac{\Delta \operatorname{Pr}(y=1)}{\Delta d}
$$

El estado inicial es que los cambios discretos así como los efectos marginales -que de igual forma se obtienen con los coeficientes estimados por la regresión- sumen 0 , como condición esencial de que la suma del evento de probabilidades sea igual al $100 \%$.

\section{Aplicación empírica}

En este apartado se indagará sobre la exploración microeconómica regional del perfil de los perceptores de remesas en México a través 
de un análisis comparativo de los años de la ENIGH 2000 y 2005, periodo en el cual las remesas repuntaron y llegaron a su nivel más alto registrado por la balanza de pagos (Huesca y Calderón, 2007). Se especifica un modelo Logit multinomial y se emplea la regionalización de Hanson (2003). Este autor establece su regionalización con base en la importancia de los flujos migratorios, de inversión extranjera directa y con los grados de apertura, por ello su justificación en este trabajo.

Partimos, primero, del contexto regional para determinar el comportamiento de los atributos que más influyen en los perceptores de las remesas, de tal manera que el individuo pertenezca a la región Frontera $(\mathrm{M}=1)$, a la Norte $(\mathrm{M}=2)$, la Centro $(\mathrm{M}=3)$, la Capital $(\mathrm{M}=4)$, la Sur $(M=5)$, y la península de Yucatán $(M=6)$, siendo la categoría base $\mathrm{M}=3$; $\mathrm{y}$ en un segundo modelo, inferimos el comportamiento del perfil del perceptor con respecto de su posición en el trabajo, como los individuos asalariados $(M=1)$, jornaleros agrícolas $(M=2)$, por cuenta propia $(M=3)$, y patrones $(M=4)$, tomando como base la categoría $\mathrm{M}=1$.

Se realizaron tres modelos variando la especificación con las variables independientes para determinar el mejor a través del Criterio de Información Bayesiano (BIC, por sus siglas en inglés) propuesto por Raftery (1996). Este criterio debe compararse con el ajuste de dos modelos (uno base y otro alternativo) y presenta tres maneras de estimación: 1. con la asociación de los grados de libertad y la desviación del modelo; 2 . con el número de regresores y la obtención de la $c h i^{2}$ de la razón de máxima verosimilitud; y 3. con el número de parámetros en el modelo (incluyendo la constante). Como lo indica Raftery (1996) y Scott y Freese (2006), cualquiera de las tres maneras de aplicar las pruebas de especificación bayesiana es correcta, y difícilmente se contradicen entre ellas, por tanto se ha seleccionado aplicar la segunda (BIC').

La prueba consiste en aplicar el criterio de que mientras más negativo el BIC', mejor será el ajuste del modelo $k$ :

$$
B I C_{k}^{\prime}=-G^{2}\left(M_{k}\right)+d f_{k}^{\prime} \ln N
$$


donde $G^{2}$ es la chi de la razón de máxima verosimilitud del modelo $M_{k}$ y $d f_{k}^{\prime}$ es igual al total de regresores en el modelo. Cuando ${ }_{B I C_{1}^{\prime}}-B_{B C_{2}^{\prime}}^{\prime}<0$, el primer modelo es preferido, en tanto que $s i_{B I C_{1}^{\prime}}-B I C_{2}^{\prime}>0$, el segundo será la mejor elección. ${ }^{3}$

Se plantean tres modelos para contrastar: el primero que explica las seis regiones, incluyendo el conjunto de variables explicativas sin las referidas a la hipótesis NELM en nuestro estudio. Las variables individuales $Z_{j}$ son la educación por niveles, la edad y edad al cuadrado para capturar la experiencia, el sexo, si es jefe del hogar, la zona de residencia, la posición del trabajador y las ramas económicas. Aquí sólo se incluyen como variables del hogar $X_{j}$ el número de miembros. El segundo modelo es igual al anterior, sólo que añade las variables NELM en $X_{j}$ y otras socioeconómicas (véase Anexo).

Las variables NELM son las referidas a la existencia de niños en el hogar, la tasa de dependencia económica, el número de miembros, si dispone de teléfono, si hay automóvil de trabajo, si se adquirieron enseres domésticos en el periodo de levantamiento de la encuesta y si cuenta con ingresos por transferencias de los programas asistenciales -Oportunidades y Procampo- (véase cuadro A1 del anexo).

El tercer modelo a contrastar cambia la variable dependiente considerando ahora la posición en el trabajo en lugar de las regiones del país, y los regresores son como en el modelo dos, con la única diferencia de que ahora entran las regiones como variables explicativas en la ecuación. En los cuadros A1, A2 y A3 del Anexo se puede observar un desglose completo de todas las variables empleadas, así como de sus principales estadísticos muestrales.

Como se aprecia en el cuadro 1 , en ambos casos el modelo que mejor se ajusta es el número $2\left(M_{k=2}\right)$. En la prueba 1 resulta ser el modelo sin variables NELM con las regiones, mientras que en la prueba 2 lo es el modelo que considera la posición en el trabajo del perceptor con variables NELM. Se calcularon las correlaciones entre las

\footnotetext{
${ }^{3}$ Raftery (1996) muestra evidencia empírica que favorece el modelo M2 por sobre el modelo M1 (BIC $C_{1}^{\prime}-B I C_{2}^{\prime}>0$ ), basado en los resultados de las diferencias siguientes: 0 - 2: débil; 2 - 6: positiva; 6 - 10: fuerte; $y>10$ : muy fuerte.
} 


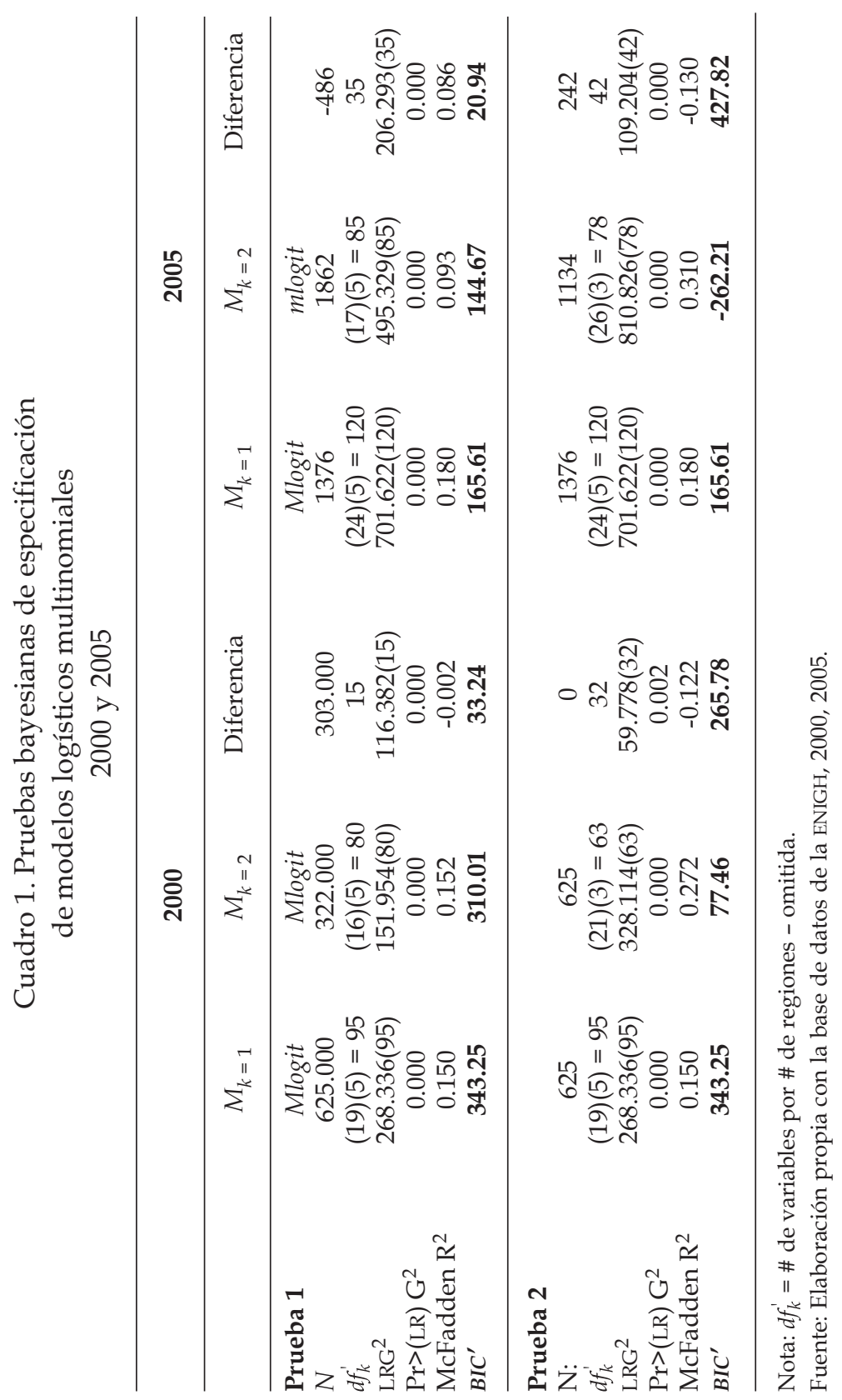


variables y se confirmó la no dependencia entre ellas, y por ende, la inexistencia de multicolinealidad. ${ }^{4}$

\section{Análisis del perfil perceptor regional}

El modelo para las regiones sin variables NELM como mejor predictor, fue calculado considerando la variable educativa en su forma continua, y después por niveles. Los impactos diferenciados de la migración en el contexto regional y en atributos como el capital humano (experiencia y escolaridad) del individuo perceptor de remesas se pueden inferir a través de las probabilidades estimadas y de los cambios discretos que se muestran en las gráficas 1 y 2 y en los cuadros 2 y 3 respectivamente para cada año.

Por regiones, podemos notar que han surgido cambios entre el 2000 y 2005 en la probabilidad de incidencia de remesas y sus cambios discretos. En función de los atributos seleccionados, es factible trazar políticas al percibir los efectos e impactos de éstos en las regiones sobre los perceptores de las remesas. Por ejemplo, de no tener estudios y pasar a tener primaria concluida, se aprecia que reduce la incidencia de las remesas, con excepción de dos regiones: en el año 2000 con la Frontera y la Norte, en tanto para 2005 se ubicó la región Capital y la Sur. A medida que los perceptores poseen más educación, se prueba que la incidencia se reduce en la región Norte, con un efecto nulo para el resto de las regiones, excepto la Yucatán y Frontera respectivamente en cada año. Este hallazgo es señal de que los individuos con mayor escolaridad en estas últimas regiones se encuentran emigrando seguramente por la falta de oportunidades que premien su capital humano.

En línea con la evidencia empírica (Quinn, 2006, y Meza et al., 2006), este trabajo muestra que existe una relación inversa entre el nivel educativo y la recepción de remesas en la región Norte en los años analizados, así como también para la Frontera en el 2000 y la Centro en el 2005; las regiones Norte y Centro consideradas como expulsoras de mano de obra por tradición. Por otro lado, se aprecia una relación

\footnotetext{
${ }^{4}$ Por razones de espacio no se muestran aquí las correlaciones ni los coeficientes de los modelos. Éstos están disponibles a petición del lector.
} 
Cuadro 2. Cambio discreto* de incidencia regional de las remesas en México, 2000

\begin{tabular}{lrrrrrrr}
\hline Variables & Frontera & Norte & Centro & Capital & Sur & Yucatán & Suma \\
\hline Edu2 & 5.68 & 7.33 & -3.16 & -0.88 & -7.44 & -1.53 & 0 \\
Edu3 & 10.36 & -8.96 & -0.56 & -1.72 & 5.30 & -4.41 & 0 \\
Edu4 & -0.25 & 0.86 & -2.74 & 1.02 & -1.23 & 2.33 & 0 \\
Edu5 & 12.42 & -30.82 & -8.96 & -5.35 & -13.84 & 46.54 & 0 \\
Sexo & 5.82 & -9.75 & -12.69 & 10.91 & 6.21 & -0.51 & 0 \\
Jefe & -12.73 & -30.43 & -33.85 & -5.28 & -13.66 & -4.04 & 0 \\
Zona & 7.95 & -1.51 & -3.44 & -3.81 & 3.80 & -2.99 & 0 \\
Size & -8.33 & 3.80 & 5.43 & -2.90 & 3.99 & -1.99 & 0 \\
Pos1 & 4.68 & 2.75 & 4.86 & -3.70 & -6.54 & -2.05 & 0 \\
Pos2 & -3.73 & -16.44 & 21.40 & -5.86 & 2.18 & 2.46 & 0 \\
Pos3 & 0.58 & 0.16 & -9.93 & 5.84 & 4.78 & -1.44 & 0 \\
Rama2 & -6.82 & 7.43 & 3.84 & 1.02 & -1.23 & -4.25 & 0 \\
Rama3 & 16.84 & -6.29 & -10.25 & 4.41 & -7.93 & 3.22 & 0 \\
Rama5 & -0.53 & -3.44 & 9.63 & -6.61 & 0.23 & 0.72 & 0 \\
Rama6 & -9.16 & 7.83 & 1.04 & 1.93 & -2.31 & 0.67 & 0 \\
\hline
\end{tabular}

* Nota: Los cambios discretos se encuentran multiplicados por cien. Fuente: Elaboración propia con la base de datos de la ENIGH, 2000.

directa entre educación y remesas sólo para la región Yucatán en el 2000; sin embargo, en el 2005 es la región Frontera la que cambia la influencia de probabilidad con respecto a la escolaridad.

En relación al nivel del hogar, los perceptores presentan mayor incidencia de las remesas cuando éste es urbano, sobre todo en la Frontera, y la probabilidad se reduce en la región Centro, Capital y Sur. Esta última se reduce en forma drástica en el 2005, lo que refleja que la mayor emigración sucede en el ámbito rural, sobre todo en aquellas regiones tradicionales de expulsión de migrantes.

Gráficamente, las probabilidades reflejan un comportamiento diferenciado. Las gráficas 1 a la 8 muestran el comportamiento probabilístico cuando cambia la edad y la educación, y se observa con respecto de la edad que las regiones de la Frontera y la Norte tienen una relación positiva en ambos años, en tanto que la región Centro presenta una relación inversa en el 2000, pero en el año 2005 cambia el patrón hacia la 
ESTUDIOS FRONTERIZOS, VOL. 10, NÚM. 19, ENERO-JUNIO 2009

Cuadro 3. Cambio discreto* de incidencia regional de las remesas en México, 2005

\begin{tabular}{lrrrrrrr}
\hline Variables & Frontera & Norte & Centro & Capital & Sur & Yucatán & Suma \\
\hline Edu2 & -2.64 & -4.55 & 5.15 & -0.43 & 3.64 & -1.17 & 0 \\
Edu3 & 3.39 & 9.87 & -2.33 & 0.26 & -9.82 & -1.37 & 0 \\
Edu4 & -0.70 & 1.46 & 0.56 & 0.32 & -4.53 & 2.89 & 0 \\
Edu5 & 11.77 & 0.29 & -6.27 & 0.97 & -7.33 & 0.56 & 0 \\
Sexo & 1.42 & 3.63 & -5.42 & -0.04 & 2.00 & -1.58 & 0 \\
Jefe & 0.58 & -3.15 & 3.05 & 1.11 & -3.02 & 1.44 & 0 \\
Zona & 6.89 & 4.54 & 0.06 & 1.91 & -10.83 & -2.58 & 0 \\
Size & -2.59 & -6.86 & 8.80 & 0.84 & 2.39 & -2.57 & 0 \\
Pos1 & -4.86 & -12.20 & 1.98 & -0.36 & 18.25 & -2.81 & 0 \\
Pos2 & 8.16 & 10.43 & -2.56 & 1.25 & -18.07 & 0.79 & 0 \\
Pos3 & -4.62 & 7.87 & 0.60 & -1.45 & -8.11 & 5.71 & 0 \\
Rama2 & -1.26 & 15.73 & 1.53 & 0.65 & -14.05 & -2.61 & 0 \\
Rama3 & -1.68 & 5.04 & -1.53 & -0.61 & -2.24 & 1.02 & 0 \\
Rama5 & 4.70 & 1.44 & -0.83 & 1.80 & -7.95 & 0.85 & 0 \\
Rama6 & -5.21 & -5.02 & -1.18 & -1.35 & 11.51 & 1.25 & 0 \\
\hline
\end{tabular}

* Nota: Los cambios discretos se encuentran multiplicados por cien. Fuente: Elaboración propia con la base de datos de la ENIGH, 2005.

región Sur y la Centro que asemejan una U invertida; sin embargo, para el caso de la escolaridad sólo la región Frontera tiene una relación positiva, y en el resto de las regiones se observa el caso opuesto en ambos años, a excepción de la región Norte en el mismo año.

Para el caso de la educación en la región Norte, se observa un nivel promedio de escolaridad de secundaria e incidencia de remesas, donde la edad impacta directamente. Por su parte, en la región Centro la edad parece afectar de forma inversa. En el caso de la edad y la región Centro en el 2005, se observa que la experiencia implica un nivel máximo promedio para los individuos, en alrededor de los 32 y 35 años, y con niveles de escolaridad promedio de secundaria, con probabilidades por arriba del 50\% en ambos casos. Las regiones de la Capital y Yucatán muestran comportamientos marginales, donde la edad parece afectar de forma inversa en la primera, pero con incidencia por debajo de $10 \%$ a partir de los 30 años. 


\section{Gráfica 1.}

Probabilidad regional de las remesas en México, 2000

(Perceptores y experiencias)

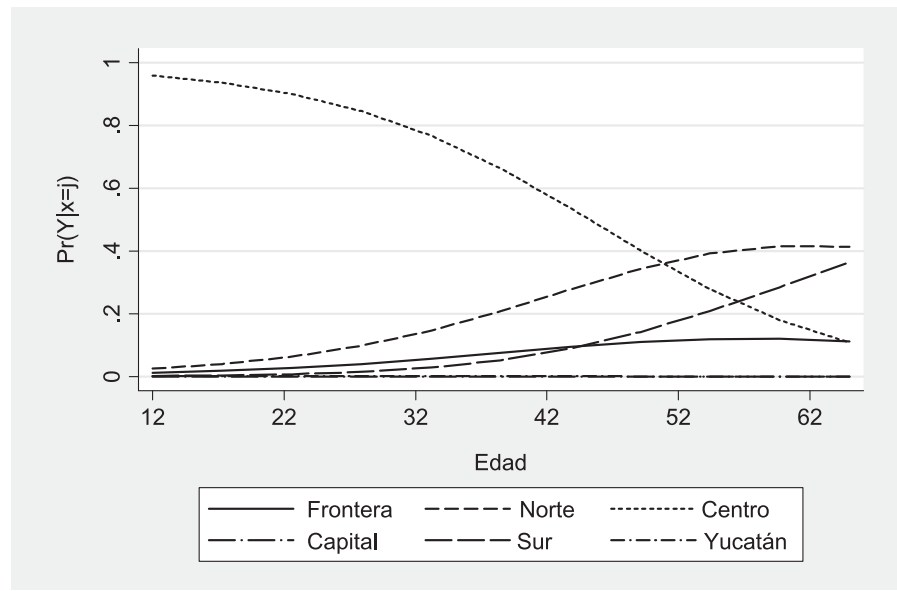

Fuente: Elaboración propia con la base de datos de la ENIGH, 2000.

\section{Gráfica 2.}

Probabilidad regional de las remesas en México, 2000 (Perceptores y escolaridad)

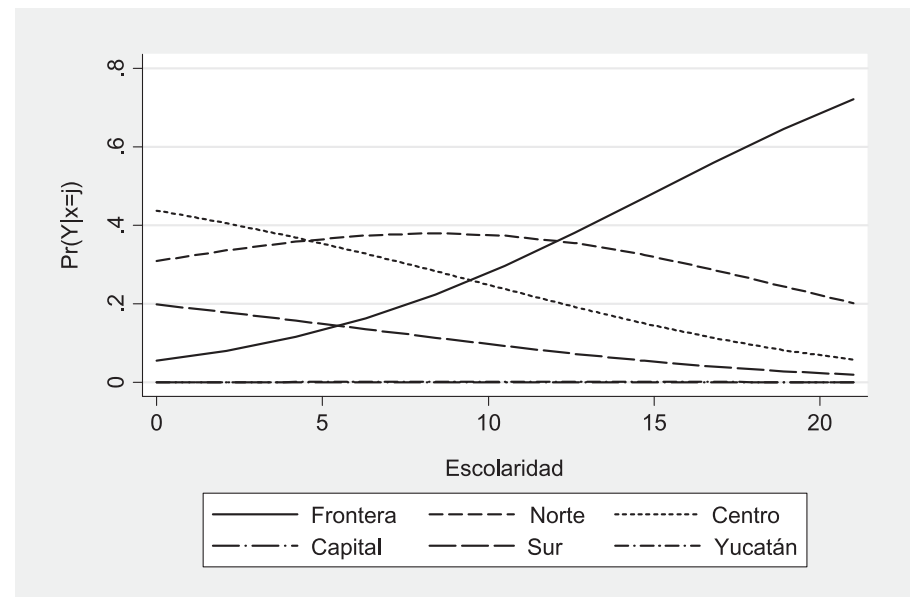

Fuente: Elaboración propia con la base de datos de la ENIGH, 2000. 


\section{Gráfica 3.}

Probabilidad regional de las remesas en México, 2000 (Edad en perceptores incluyendo NELM)

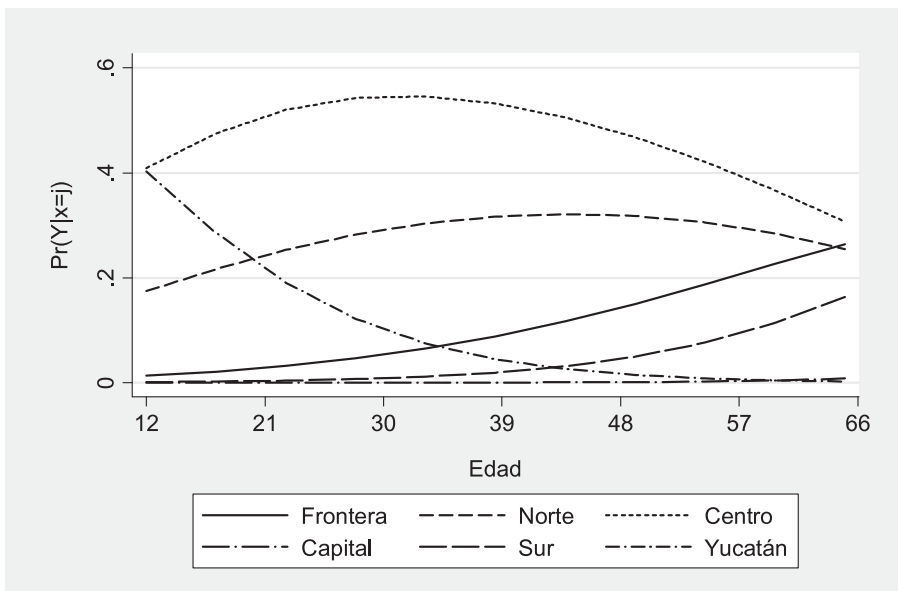

Fuente: Elaboración propia con la base de datos de la ENIGH, 2000.

\section{Gráfica 4.}

Probabilidad regional de las remesas en México, 2000 (Educación en perceptores incluyendo NELM)

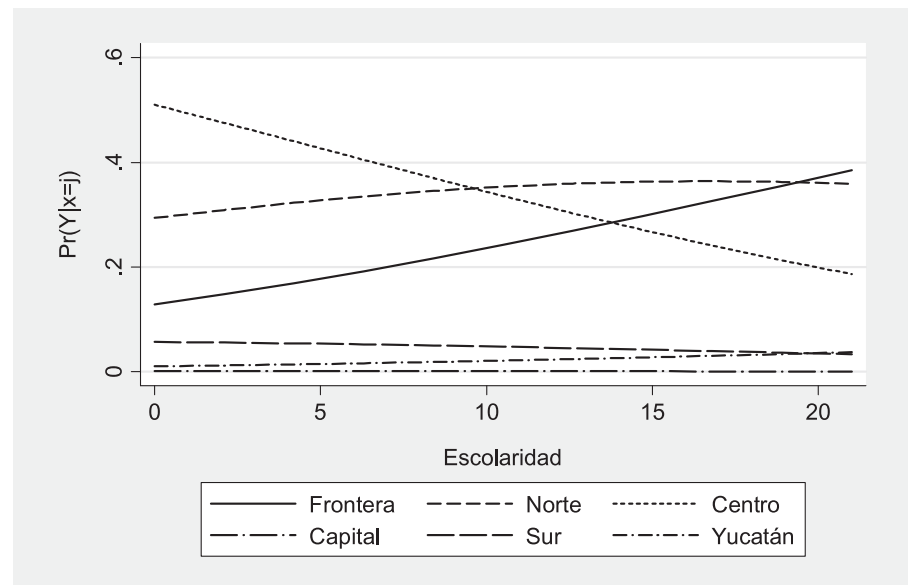

Fuente: Elaboración propia con la base de datos de la ENIGH, 2000. 


\section{Gráfica 5.}

Probabilidad regional de las remesas en México, 2000

(Perceptores y experiencias)

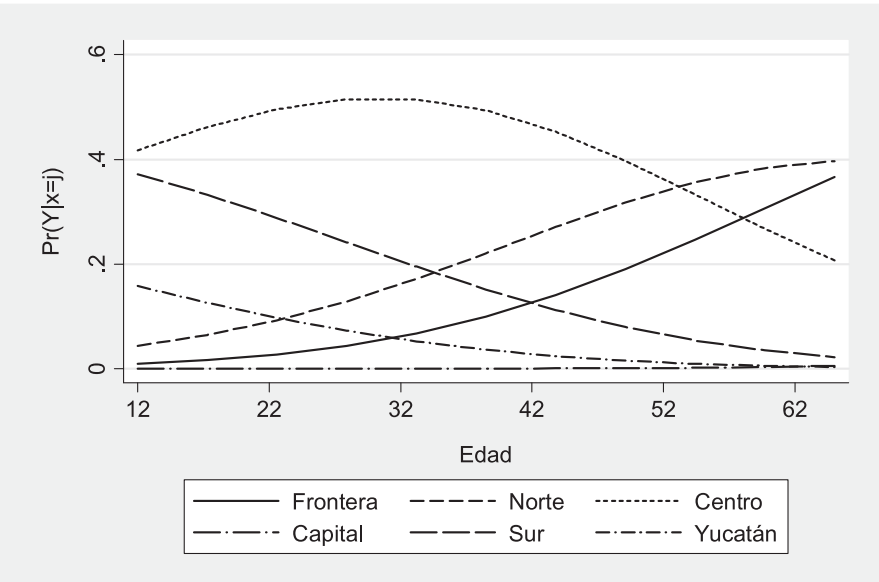

Fuente: Elaboración propia con la base de datos de la ENIGH, 2000.

\section{Gráfica 6.}

Probabilidad regional de las remesas en México, 2000

(Perceptores y escolaridad)

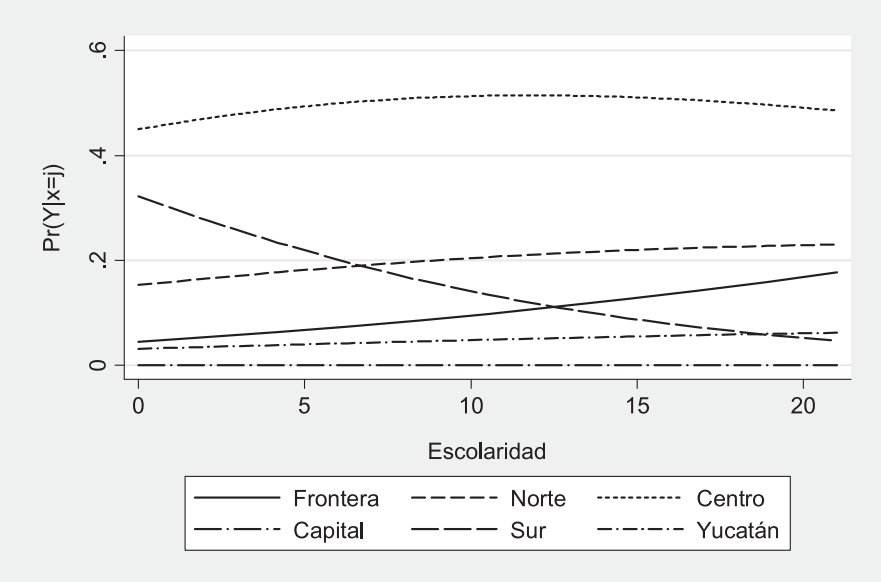

Fuente: Elaboración propia con la base de datos de la ENIGH, 2000. 


\section{Gráfica 7.}

Probabilidad regional de las remesas en México, 2000

(Perceptores y experiencias incluyendo NELM)

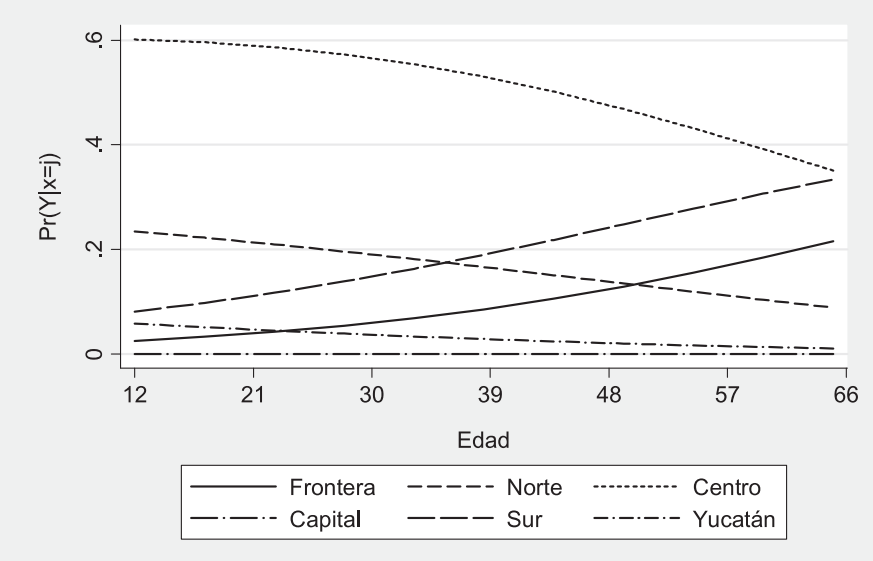

Fuente: Elaboración propia con la base de datos de la ENIGH, 2000.

\section{Gráfica 8.}

Probabilidad regional de las remesas en México, 2000

(Perceptores y escolaridad incluyendo NELM)

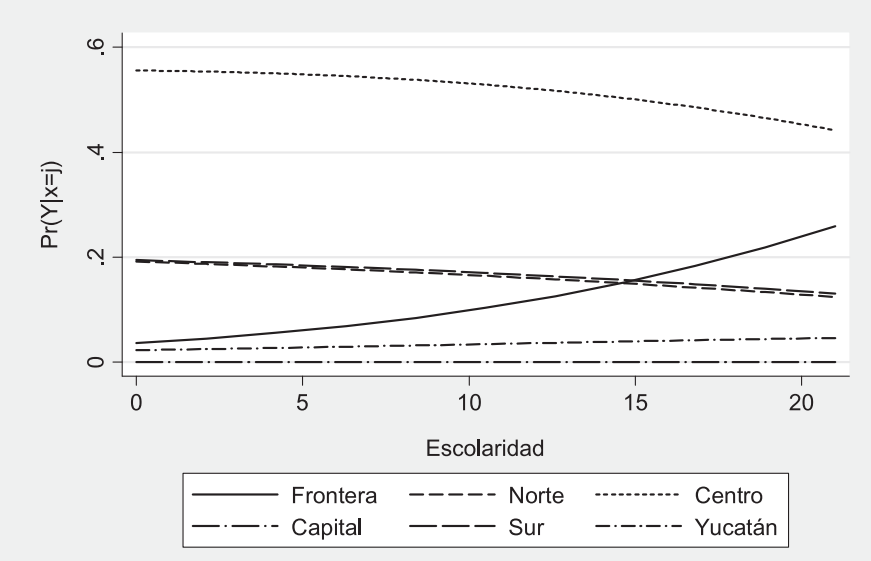

Fuente: Elaboración propia con la base de datos de la ENIGH, 2000. 
Podemos establecer que la región Centro presenta características relevantes en la población joven y de adultos jóvenes, en tanto la región Norte premia con mayor intensidad la experiencia a partir de los 40 y hasta los 60 años en ambos años. En el 2005 este comportamiento es similar para los individuos ubicados en la Frontera.

$\mathrm{Al}$ incluir las variables bajo el enfoque de la NELM, se puede observar que existe una relación directa con la edad y la educación para las regiones de la Frontera y la Sur en ambos años, con un promedio máximo de edad a los 40 años, pero no ocurre los mismo con la educación ya que se muestran comportamientos marginales a la par con la Capital y Sur en el 2000, mientras que en el caso del 2005 sólo sucede en la Capital.

\section{Análisis del perfil perceptor por posición en el trabajo}

En el segundo modelo se incluyen ahora las regiones pero como regresores, y las variables del hogar que resaltan el indicador del gasto en bienes duraderos y la posesión de otros satisfactores como proxies de la hipótesis NELM. El análisis multinomial de las probabilidades nos permite detectar las diferencias ocurridas al interior de cada región, considerando la influencia que presentan sobre la posición en el trabajo de los perceptores: asalariados, jornaleros, cuenta propia y patrones.

De acuerdo a los cuadros 4 y 5 , el cambio de probabilidad muestra que tiende a disminuir la incidencia de las remesas -y emigraciónconexamente en los niveles educativos para la posición de jornaleros y por cuenta propia, mientras se incrementa de forma sustancial para los empleados y patrones. Un hallazgo relevante es que el impacto se incrementa de forma sustancial para el año 2005 para el empleado en la Frontera, el Norte y la Capital, mientras que la posición por cuenta propia presenta la mayor incidencia en la región Sur del país con cambios de probabilidad de 28 puntos porcentuales.

En la posición de jornaleros, pasar a tener una familia numerosa, con un número de hijos mayor a la media, y casa propia, presenta incrementos en la probabilidad de ser perceptor de remesas en el 2005. Variables como tener camioneta de trabajo impacta positivamente sólo 
ESTUDIOS FRONTERIZOS, VOL. 10, NÚM. 19, ENERO-JUNIO 2009

Cuadro 4. Cambio discreto* de incidencia de las remesas por posición en el trabajo en México, 2000

\begin{tabular}{lrrrrr}
\hline Variables & Empleado & Jornalero & Cuenta propia & Patrón & Suma \\
\hline Edu2 & -24.78 & 4.16 & 19.98 & 0.64 & 0 \\
Edu3 & 0.28 & -5.46 & -2.86 & 8.04 & 0 \\
Edu4 & 12.79 & -5.28 & -7.50 & -0.02 & 0 \\
Edu5 & 5.44 & -5.17 & -28.59 & 28.33 & 0 \\
Sexo & 5.51 & -5.65 & 6.02 & -5.88 & 0 \\
Jefe & -61.28 & -5.12 & -28.32 & -5.28 & 0 \\
Ecivil & -33.76 & 7.71 & 21.86 & 4.20 & 0 \\
Zona & 16.48 & -3.21 & -10.43 & -2.84 & 0 \\
Frontera & 8.46 & -2.04 & -2.89 & -3.54 & 0 \\
Norte & -2.42 & -3.23 & 2.82 & 2.83 & 0 \\
Centro & 15.23 & 2.28 & -14.93 & -2.58 & 0 \\
Capital & -30.54 & -5.31 & 36.60 & -0.76 & 0 \\
Sur & -31.31 & 4.35 & 24.77 & 2.19 & 0 \\
\hline Variables NELM & & & & & 0 \\
\hline Size & -11.66 & 4.97 & 7.47 & -0.79 & 0 \\
Niños & -5.06 & 2.17 & 5.66 & -2.77 & 0 \\
Casa & 3.02 & -2.83 & 1.06 & -1.24 & 0 \\
Truck & -7.86 & -1.06 & 4.36 & 4.55 & 0 \\
Tran & -12.14 & 4.52 & 8.27 & -0.65 & 0 \\
Pro & -43.92 & 6.72 & 20.88 & 16.32 & 0 \\
\hline
\end{tabular}

* Nota: Los cambios discretos se encuentran multiplicados por cien.

Fuente: Elaboración propia con la base de datos de la ENIGH, 2000.

para cuenta propia y patrones en ambos años, y la mayor parte de las variables como el gasto en bienes durables para el caso del 2005, incrementa la participación en las remesas de los individuos que trabajan como asalariados, y que incluso reciben alguna transferencia gubernamental como el programa Procampo. ${ }^{5}$

${ }^{5}$ En la prueba 2 de especificación, el modelo no escogido reveló que ser jornalero, en el caso de las regiones tradicionales hacia la migración, muestra una reducción en 2.8 puntos para la región Centro y mucho más elevada para la Sur, con un 
LUIS HuESCA REYNOSO/ANÁLISIS REGIONAL DE LAS REMESAS

Cuadro 5. Cambio discreto* de incidencia de las remesas por posición en el trabajo en México, 2005

\begin{tabular}{|c|c|c|c|c|c|}
\hline Variables & Empleado & Jornalero & Cuenta propia & Patrón & Suma \\
\hline Edu2 & -22.12 & 6.82 & 13.34 & 1.95 & 0 \\
\hline Edu3 & 19.34 & 0.09 & -16.35 & -3.09 & 0 \\
\hline Edu4 & 33.59 & -7.39 & -23.35 & -2.85 & 0 \\
\hline Edu5 & 39.81 & -15.71 & -31.09 & 6.99 & 0 \\
\hline Sexo & -0.84 & 18.95 & -22.60 & 4.49 & 0 \\
\hline Jefe & -19.33 & -4.18 & 19.31 & 4.21 & 0 \\
\hline Ecivil & 5.16 & 1.31 & -4.00 & -2.47 & 0 \\
\hline Zona & 34.69 & -7.31 & -26.18 & -1.20 & 0 \\
\hline Frontera & 23.08 & -9.04 & -9.86 & -4.18 & 0 \\
\hline Norte & 11.67 & 3.76 & -14.37 & -1.06 & 0 \\
\hline Centro & -0.71 & 2.56 & -2.25 & 0.39 & 0 \\
\hline Capital & 16.27 & -14.62 & 3.07 & -4.72 & 0 \\
\hline Sur & -26.61 & -5.60 & 27.90 & 4.31 & 0 \\
\hline \multicolumn{6}{|c|}{ Variables NELM } \\
\hline Size & 6.42 & 4.42 & -8.77 & -2.06 & 0 \\
\hline Niños & 4.03 & 3.58 & -6.70 & -0.90 & 0 \\
\hline Casa & -31.10 & 3.62 & 23.76 & 3.72 & 0 \\
\hline Tel & 17.54 & -4.61 & -14.69 & 1.76 & 0 \\
\hline Truck & -6.65 & -1.36 & 5.23 & 2.77 & 0 \\
\hline Tarj & 21.09 & -9.88 & -16.31 & 5.11 & 0 \\
\hline Refri & 22.13 & -10.32 & -13.52 & 1.72 & 0 \\
\hline Lava & 19.09 & -4.01 & -16.16 & 1.08 & 0 \\
\hline Tran & 0.82 & -3.39 & 3.53 & -0.96 & 0 \\
\hline Pro & 3.70 & 1.33 & -3.10 & -1.94 & 0 \\
\hline
\end{tabular}

* Nota: Los cambios discretos se encuentran multiplicados por cien. Fuente: Elaboración propia con la base de datos de la ENIGH, 2005.

efecto marginal de 18.3 puntos en la Sur. Esto último es un hallazgo que permite inferir que las remesas están arraigando población en las regiones que por tradición exportan mano de obra hacia los EE. UU.; por otro lado, el programa Procampo no permite reducir la emigración de trabajadores para las regiones de la Frontera, Norte y Centro, en tanto que la región Sur sí presenta un efecto reductor con un cambio de probabilidad por el orden de 13.2 puntos porcentuales. 
El hecho de que la variable zona presente un impacto negativo en su cambio discreto en todas las ocupaciones con excepción de los empleados, es señal de que los trabajadores rurales en esas categorías laborales que pasan a ser urbanos presentan cada vez un mayor arraigo entre 2000 y 2005; a diferencia de aquellos ubicados en las zonas urbanas como empleados, con uno de los aumentos más elevados en el cambio discreto. Si un trabajador -empleado- pasa a pertenecer a la zona urbana en el 2000, presenta un cambio de 16.48 puntos en su probabilidad y en el 2005 presenta un cambio de 34.7 puntos en la incidencia de las remesas.

En el 2000, se presenta un incremento tanto en los jornaleros como en los individuos por cuenta propia, en 4.7 y 7.4 puntos en su probabilidad, y en relación con la posición de los empleados y los patrones se reduce en -11.6 y -0.7 puntos su probabilidad. De forma similar ocurre con los perceptores que residen en hogares con un número de niños mayor a la media; sin embargo, no ocurre lo mismo en el 2005. Como era de esperarse, en el 2005 el impacto de pasar a residir en un hogar con un número mayor a la media de miembros residentes, refleja un incremento tanto para los empleados como para los jornaleros agrícolas, en 6.4 y 4.4 puntos, y una reducción de probabilidad para las categorías por cuenta propia y los patrones.

Siguiendo la hipótesis NELM, en el 2000 el hecho de tener casa propia y automóvil aumenta la probabilidad para los trabajadores por cuenta propia y los reduce fuertemente para los jornaleros. Para el 2005, el hecho de tener casa propia, carro, teléfono, refrigerador, lavadora y usar tarjeta en las compras incrementa la probabilidad para los patrones, mientras que la reduce para los jornaleros.

Las gráficas 9 y 10 muestran la incidencia de las remesas, con la influencia de la edad y la escolaridad en la posición del trabajo por regiones. En el 2005 se nota un comportamiento similar para los asalariados tanto a nivel nacional como en las regiones de la Frontera, la Norte y Centro. Las probabilidades tienen una relación directa y lineal en las regiones Centro y Sur con respecto de los perceptores asalariados, mientras que ésta se observa inversa para aquellos en la posición de jornaleros en la región Centro, lo que implica que son los más jóvenes los emigrantes y perceptores de remesas. 


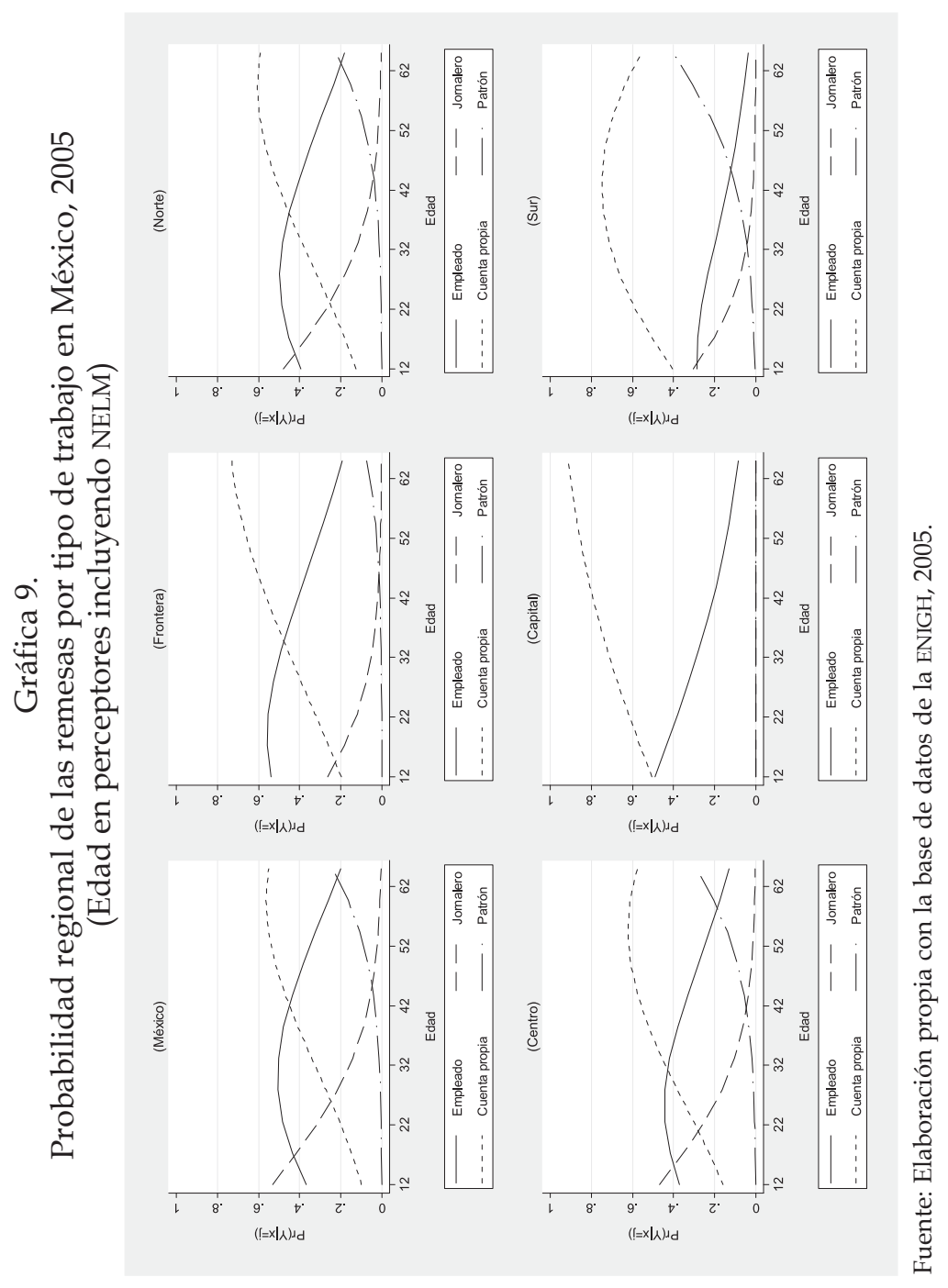




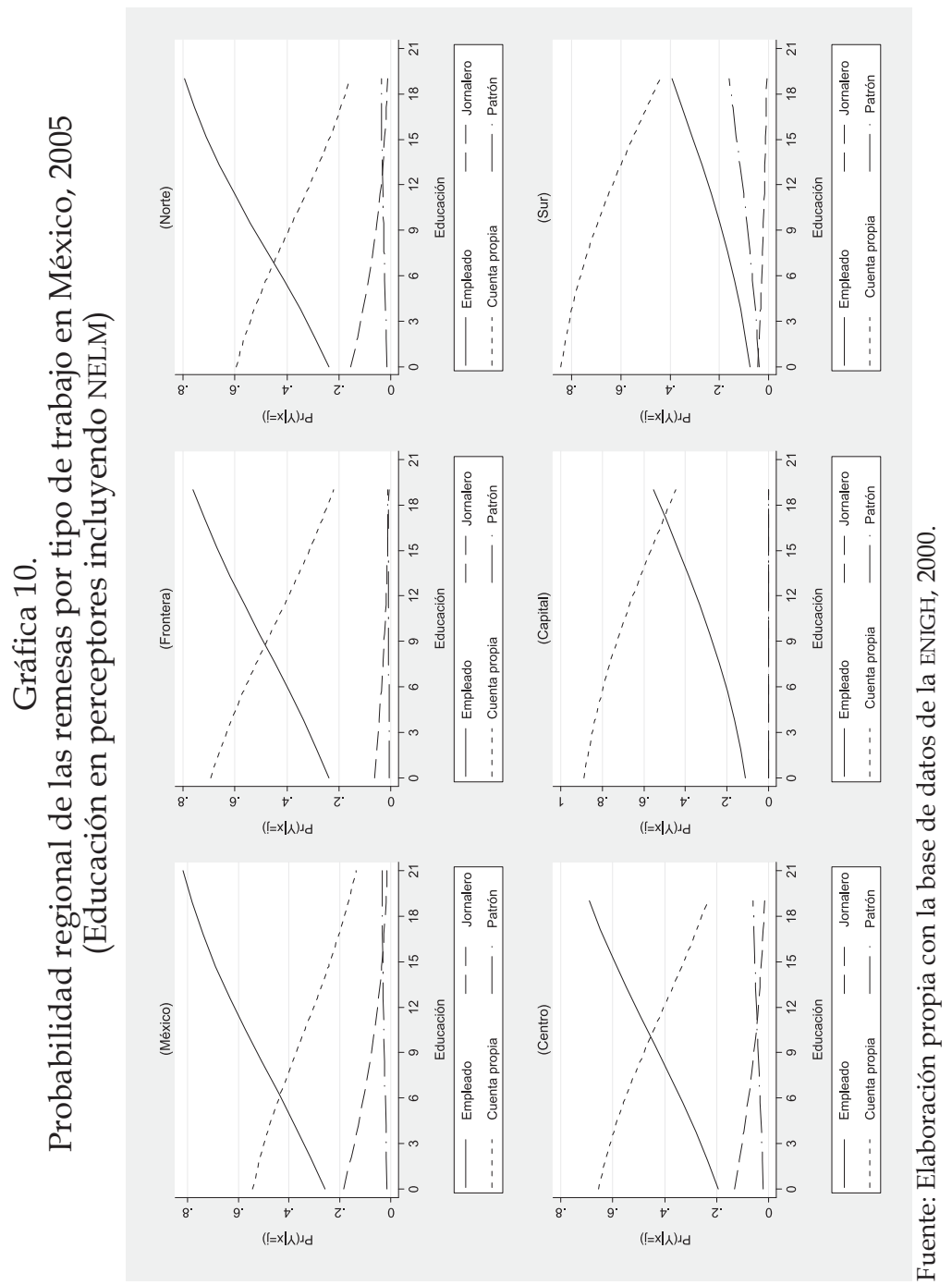


En relación con la educación, las probabilidades muestran una relación directa en la posición por cuenta propia, e inversa con respecto de los asalariados en todas las regiones; respecto de los perceptores en la posición de jornaleros para las regiones Norte y Centro, se observa una relación inversa y de forma directa en la región Sur.

En todos los casos, la evidencia está en línea con los trabajos de Quinn (2006), Chávez (2006a y 2006b) y Meza et al. (2006), donde se observa que la edad aumenta la probabilidad de remesas y la emigración en los individuos alrededor de los 32 años, edad en la cual comienza a decrecer la incidencia. También la evidencia encuentra una relación inversa entre la escolaridad y la migración hacia los Estados Unidos (Quinn, 2006), y que en el caso de este trabajo, se cumple en la región Centro y Sur; mientras que presenta un efecto positivo para la Frontera y de baja intensidad en el resto de las regiones consideradas.

En el caso de China, la evidencia de Brauw et al. (2001) indica que la participación de la migración en el nivel de ingreso familiar rural aumenta hasta un $30 \%$, estimulando la producción agrícola en dichas zonas. Las características de la migración en China es que la familia con suficiente disponibilidad de trabajo tiende a enviar a más de un miembro a emigrar, reduciendo así el número de trabajadores en la comunidad, y que en su mayoría son hombres jóvenes y con mayor educación que el promedio. En este caso, nuestra evidencia para México muestra de forma similar esta situación en el caso de las regiones Centro y Sur, con un aumento en la probabilidad para los hogares con más miembros, sin embargo, con menor educación. Interesante es el suceso de la Frontera, donde la mayor escolaridad indica, si bien con incidencia moderada, una relación directa con las remesas, con probabilidades que superan el $20 \%$ para individuos que tienen grado de estudios superiores.

\section{Conclusiones}

En este trabajo se estudian las cualidades individuales y el perfil microeconómico de los perceptores de remesas en el seno del hogar. Entre los aspectos que se toman en consideración están el capital humano, la experiencia laboral y la estructura de empleo de los miem- 
bros del hogar. Por regiones, se observa que han surgido cambios importantes del 2000 al 2005, y que existe una relación inversa entre el nivel educativo y la recepción de remesas en aquellas zonas que tradicionalmente son expulsoras de mano de obra -como la Norte y la Centro-; mientras que sólo para la Yucatán y Frontera, respectivamente, se observa la existencia de una relación directa entre educación y recepción de remesas. Esto nos indica, por un lado, que los individuos que cuentan con mayor preparación en estas últimas regiones tienden a emigrar por la falta de oportunidades locales que premien su capital humano, y por el otro, que las políticas educativas han impactado de forma positiva en el esfuerzo de arraigo y permanencia de la población emigrante en las regiones Centro y Norte del país.

Los perceptores urbanos de remesas son los que tienen mayor incidencia regional, y el único caso en que se reduce la probabilidad de manera drástica, es el correspondiente a la región Sur en ambos años, como resultado de que en dicha región la mayor emigración en sus localidades ha sido de origen rural en años recientes.

Podemos establecer que la población de la región Centro está integrada en su mayoría por jóvenes y adultos jóvenes, mientras que en la Norte las mayores remesas se presentan en la población con experiencia a partir de los 40 y hasta los 60 años; un comportamiento similar vemos en los individuos ubicados en la región Frontera.

Un hallazgo que requiere mayor precisión son los impactos de los programas asistenciales Oportunidades y Procampo en los hogares que reciben remesas, ya que sus efectos no son claros, y no presentan una significancia estadística uniforme. Podría pensarse que esto se debe a una asignación inexacta de estos recursos por parte del gobierno federal, pero esta evidencia requiere ser analizada con mayor profundidad, analizando la estructura de las citadas transferencias por niveles de ingresos.

Siguiendo la hipótesis NELM, se observa que los hogares numerosos sí aumentan efectivamente la incidencia de las remesas, al igual que los niños y tener casa propia en el caso de los jornaleros. Se observa la necesidad de aplicar una política pública cuyos apoyos financieros, crediticios y de infraestructura se orienten de manera prioritaria a las zonas que tradicionalmente son receptoras de remesas, cuyas po- 
blaciones objetivo en la región Centro están integradas por los colectivos de adultos jóvenes, mientras que en la Norte por los de mayor edad. Mientras en la región Sur se observa una relevancia en el trabajo por cuenta propia, donde apoyar a dichos grupos de trabajadores permitiría aprovechar las capacidades emprendedoras con mayor rentabilidad social y económica, en las actividades productivas y de bienestar de las familias receptoras de remesas.

\section{Bibliografía}

Aguirre Ochoa, J. I. y Zoe Tamar Infante (2005), "Remesas y microempresas: un análisis estadístico para el caso de Michoacán", en Jerjes I. Aguirre Ochoa y Zoe Tamar Infante, Remesas e inversión: consideraciones para el caso mexicano, Universidad Michoacana de San Nicolás de Hidalgo, Instituto de Investigaciones Económicas y Empresariales, Consorcio de Centros de Estudios APEC.

Baudassé, T. y C. Calderón (2006), “Desigualdad económica e integración comercial del sector agrícola en los países en vías de desarrollo", mimeo, Universidad de Orleans, Francia.

Bourdieu, P. (1980), "Le capital social, notes provisoires”, Actes de la Recherche en Sciences Sociales, pp. 2-3.

Brauw, Alan de, J. Edward Taylor y Scott Rozelle (2001), “Migration and Incomes in Source Communities: A New Economics of Migration Perspective from China", mimeo, University of California.

Calderón, Cuauhtémoc y E. Mendoza (2005), “ ¿Existen efectos de las remesas y la migración hacia los EE. UU. sobre el crecimiento de México?", en Jerjes I. Aguirre Ochoa y Zoe Tamar Infante, Remesas y desarrollo en México, Instituto de Investigaciones Económicas y Empresariales, Universidad Michoacana de San Nicolás de Hidalgo, México.

(2006), “Impactos regionales de las remesas en el crecimiento económico de México", Papeles de Población, núm. 50, México, octubre-diciembre.

(2006), “Apertura económica, salarios y migración internacional”, Análisis Económico, vol. XXI, primer cuatrimestre, núm. 46, México. 
Calderón, Cuauhtémoc y L. Hernández (2007), “Las remesas y sus efectos sobre el tipo de cambio real y la brecha del PIB mexicano de 1999 a 2005", en Jerjes I. Aguirre Ochoa, José C. Lenin Navarro Chavez y Víctor A. Acevedo Valerio (coords.), Migración y Remesas, Instituto de Investigaciones Económicas y Empresariales, Universidad Michoacana de San Nicolás de Hidalgo, México.

Carriles R., Jorge, Francisco Reyes G., Alberto Vargas A. y Gabriel Vera (1991), "Las remesas familiares provenientes del exterior. Marco conceptual y metodología de medición", Documento de Trabajo 67, Banco de México, México, julio, pp. 1-72.

Chávez G., Fernando (2006a), “Tres aspectos de la evolución de las remesas familiares en México, según la ENIGH, 1984-2004", Análisis Económico, vol. XXI (46), ene.-abr.

(2006b), "Nuevos elementos para definir el perfil de los hogares mexicanos receptores de remesas, 1984-2004", ponencia presentada en el V Congreso Nacional de la Asociación Mexicana de Estudios del Trabajo, Oaxtepec, Morelos, 17 al 19 de mayo.

Fei, J. C. H. y G. Ranis (1961), "A Theory of Economic Development", American Economic Review, vol. 51, pp. 533-565.

Fields, Gary (1975), "Rural-Urban Migration, Urban Unemployment, and Underemployment, and Job Search Activity in LDC's", Journal of Development Economics, vol. 2, núm. 2, pp. 165-187.

Hanson, Gordon (2003), "What has Happened to Wages in Mexico since NAFTA? Implications for Hemispheric Free Trade", NBER Working Paper núm. 9563.

Harris, J. R. y M. P. Todaro (1970), "Migration, Unemployment and Development: A Two-sector Analysis", American Economic Review, pp. 126-142.

Huesca y C. Calderón (2007), “Exploración microeconómica regional del perfil de los perceptores de las remesas en México", en Jerjes Izcoátl Aguirre (coord.), Remesas y desarrollo económico en México, Universidad Michoacana de San Nicolás de Hidalgo, UCLA, El Colegio de Tlaxcala, diciembre.

Lewis, W.A. (1954), "Economic Development with Unlimited Surplus of Labour", The Manchester School of Economic and Social Studies, vol. 20, pp. 139-92. 
Meza, Liliana, Carla Pederzini Villarreal y Sarah Martínez Pellegrini (2006), "El autoempleo como mecanismo de arraigo de la población en México; caso de cuatro localidades", Estudios Demográficos y Urbanos, vol. 21, núm. 3, pp. 547-623.

Muñoz, Alma Rosa Jumilla (2006a), “Impacto macroeconómico de las remesas familiares en México, 1950-2004", tesis doctoral, Universidad Autónoma de Barcelona.

(2006b), "Remesas familiares y su impacto en el crecimiento económico, 1950-2004" , Análisis Económico, vol XXI, núm. 46, ene.abr., pp. 23-57.

Quinn, Michael A. (2006), "Relative Deprivation Wage Differentials and Mexican Migration", Review of Development Economics, pp. 135-153.

Raftery, A. E. (1996), "Bayesian Model Selection in Social Research", en P. V. Marsden (ed.), Sociological Methodology, vol. 26, Oxford, Blackwell, pp. 111-163.

Schiff, Maurice (1999a), “Trade, Migration and Welfare: The Impact of Social Capital”, Policy Research Working Paper, The World Bank. (1999b), "Labor Market Integration in the Presence of Social Capital", Policy Research Working Paper, The World Bank. (2002), "Love thy Neighbor: Trade, Migration, and Social Capital", European Journal of Political Economy, vol. 18, pp. 87-107.

Stark, Oded y D. Bloom (1985), "The New Economics of Labor Migration", American Economic Review, núm. 75, pp. 173-178.

E. Taylor y S. Yitzhaki (1986), "Remmitances and Inequality", The Economic Journal, vol. 96, núm. 383, pp. 722-740.

y Robert E. B. Lucas (1988), "Migration, Remittances, and the Family", Economic Development and Cultural Change, vol.36, núm. 3, pp. 465-481.

Stark, Oded y You Quiang Wang (2000), "A Theory of Migration as a Response to Relative Deprivation", German Economic Review, vol. 1, núm. 2, pp. 131-143.

Sana, Mariano y Douglas S. Massey (2005), "Household Composition, Family Migration, and Community Context: Migrant Remittances in four Countries", Social Science Quarterly, vol. 86, num. 2, pp. 509-565. 
Scott, J. y J. Freese (2006), "Estimation, Testing, Fit, and Interpretation", en Regression Models for Categorical Dependent Variables Using Stata, STATA-Press, College Station, Texas, pp. 106-113.

Taylor, Edward y Philip L. Martin (2001), "Human Capital: Migration and Rural Population Change", en Handbook of Agricultural Economics, vol. 1, Nueva York, pp. 457-511.

Todaro, M. (1995), Reflections on Economic Development: Selected Essays of Michael Todaro, Edward Elgar Publishing Co., Vermont, EE. UU.

Tuirán, Rodolfo (2001), “Dinámica reciente de la migración MéxicoEstados Unidos”, Mercado de Valores, núm. 8, Nacional Financiera, México.

Woodruff, C. y R. Zenteno (2001), “Remittances and Microenterprises in México", Documento de trabajo, San Diego, University of California.

Zárate-Hoyos, G. (2004), Remesas de los mexicanos y centroamericanos en los Estados Unidos, El Colegio de la Frontera Norte, Miguel Ángel Porrúa, México.

Recibido en julio de 2008 Aceptado en diciembre de 2008 


\section{Anexo}

Cuadro A1. Conceptos de las variables utilizadas en los perceptores de remesas a través de la ENIGH, 2000 y 2005

\begin{tabular}{ll}
\hline Variables & Conceptos \\
\hline $\begin{array}{l}\text { Individuales } \\
Z_{j}\end{array}$ & \\
\hline Frontera & Baja California, Chihuahua, Coahuila, Nuevo León, \\
& Sonora, Tamaulipas. \\
Norte & Aguascalientes, Baja California Sur, Durango, Nayarit, \\
& SLP, Sinaloa, Zacatecas. \\
Centro & Colima, Guanajuato, Hidalgo, Jalisco, Michoacán, \\
& Morelos, Puebla, Querétaro, Tlaxcala, Veracruz. \\
Capital & Distrito Federal y Estado de México. \\
Sur & Oaxaca, Guerrero y Chiapas. \\
Yucatán & Campeche, Tabasco, Quintana Roo, Yucatán. \\
Esco1** & Sin estudios. \\
edu2 & Primaria terminada. \\
edu3 & Secundaria terminada. \\
edu4 & Bachillerato terminado. \\
edu5 & Profesional o postgrado. \\
edad & Continua de 12 a 65 años. \\
edad2 & Edad al cuadrado. \\
sexo & Género del perceptor. \\
jefe & Jefe de familia. \\
ecivil & Estado civil (Casado = 1; otro = 0). \\
zona & Zona (urbana = 1; rural = 0). \\
pos1 & Obrero o empleado o asalariado. \\
pos3 & Jornalero rural. \\
pos4 & Trabajador por cuenta propia. \\
Rama1 & Patrón o dueño de un negocio. \\
Rama2 & Ind. de la transformación. \\
Rama3 & Construcción. \\
Rama4 & Comercio. \\
Rama5 & Transporte y comunicaciones. \\
& $\begin{array}{l}\text { Servicios. } \\
\text { Agricultura y actividad primaria. }\end{array}$ \\
\hline & \\
\hline
\end{tabular}


(...continuación)

Cuadro A1. Conceptos de las variables utilizadas en los perceptores de remesas a través de la ENIGH, 2000 y 2005

\begin{tabular}{|c|c|}
\hline Variables & Conceptos \\
\hline \multicolumn{2}{|c|}{ Variables NELM: $\operatorname{Hogar}_{X j}$} \\
\hline size & $\begin{array}{l}\text { Número de miembros en el hogar mayor a la media } \\
\text { nacional. }\end{array}$ \\
\hline niños & $\begin{array}{l}\text { Número de niños menores en el hogar mayor a la media } \\
\text { nacional. }\end{array}$ \\
\hline casa & Tenencia del hogar $($ Propio $=1 ;$ otro $=0)$ \\
\hline Depen ** & $\begin{array}{l}\text { Tasa de dependencia económica por encima de la media } \\
\text { nacional. }\end{array}$ \\
\hline $\mathrm{Tel}$ * & Teléfono. \\
\hline Truck & Camioneta pick up $\mathrm{u}$ otro similar de trabajo. \\
\hline Tarj * & Usa tarjeta de crédito o débito. \\
\hline Refri * & Tiene refrigerador. \\
\hline Lava * & Tiene lavadora. \\
\hline Oportun. & Tiene transferencias de Oportunidades. \\
\hline Procampo & Tiene transferencias de Procampo. \\
\hline
\end{tabular}

*Variables agregadas en el modelo del 2005.

**Variables que en el modelo del 2005 se llaman esco1= edu1, y depen= depatrio. Fuente: Elaboración propia con base en la ENIGH, 2000 y 2005. 
Cuadro A2.Resumen de la base de datos.

Perceptores de remesas e indicadores socioeconómicos, ENIGH, 2000

\begin{tabular}{|c|c|c|c|c|c|}
\hline Variable & Media & Desv. std. & Mínimo & Máximo & Obs. \\
\hline edad & 50.529 & 15.96 & 15 & 97 & 625 \\
\hline edad2 & 28007.845 & 1664.792 & 225 & 9409 & 625 \\
\hline Escolaridad & 2.993 & 3.619 & 0 & 21 & 625 \\
\hline edu2 & 0.484 & 0.500 & 0 & 1 & 625 \\
\hline edu3 & 0.062 & 0.242 & 0 & 1 & 625 \\
\hline edu4 & 0.030 & 0.171 & 0 & 1 & 625 \\
\hline edu5 & 0.009 & 0.097 & 0 & 1 & 625 \\
\hline sexo & 1.280 & 0.453 & 0 & 2 & 625 \\
\hline jefe & 1 & 0 & 1 & 1 & 625 \\
\hline ecivil & 0.468 & 0.499 & 0 & 1 & 625 \\
\hline zona & 0.435 & 0.496 & 0 & 1 & 625 \\
\hline size & 0.368 & 0.482 & 0 & 1 & 625 \\
\hline niños & 0.398 & 0.489 & 0 & 1 & 625 \\
\hline casa & 0.572 & 0.495 & 0 & 1 & 625 \\
\hline depen & 1.542 & 1.225 & 0 & 7 & 625 \\
\hline truck & 0.425 & 0.494 & 0 & 1 & 625 \\
\hline Oportun. & 0.201 & 0.401 & 0 & 1 & 625 \\
\hline Procampo & 0.070 & 0.256 & 0 & 1 & 625 \\
\hline pos1 & 0.612 & 0.487 & 0 & 1 & 625 \\
\hline pos 2 & 0.051 & 0.220 & 0 & 1 & 625 \\
\hline pos3 & 0.283 & 0.450 & 0 & 1 & 625 \\
\hline pos4 & 0.052 & 0.223 & 0 & 1 & 625 \\
\hline rama1 & 0.090 & 0.286 & 0 & 1 & 322 \\
\hline rama2 & 0.496 & 0.217 & 0 & 1 & 322 \\
\hline rama3 & 0.136 & 0.344 & 0 & 1 & 322 \\
\hline rama4 & 0.024 & 0.155 & 0 & 1 & 322 \\
\hline rama5 & 0.201 & 0.402 & 0 & 1 & 322 \\
\hline rama6 & 0.496 & 0.500 & 0 & 1 & 322 \\
\hline
\end{tabular}

* Las variables que no suman $1(100 \%)$ se refieren por diferencia a los No Especificados en la encuesta, quedando agrupados fuera del sector considerado. Fuente: Elaboración propia con base en la ENIGH, 2000. 
Cuadro A3. Resumen de la base de datos.

Perceptores de remesas e indicadores socioeconómicos, ENIGH, 2005

\begin{tabular}{|c|c|c|c|c|c|}
\hline Variable & Media & Desv. std. & Mínimo & Máximo & Obs. \\
\hline edad & 35.699 & 15.707 & 12 & 65 & 1865 \\
\hline edad2 & 1520.987 & 1211.875 & 144 & 4225 & 1865 \\
\hline Escolaridad & 7.653 & 4.258 & 0 & 19 & 1865 \\
\hline edu1 & 0.115 & 0.214 & 0 & 1 & 1865 \\
\hline edu2 & 0.460 & 0.498 & 0 & 1 & 1865 \\
\hline edu3 & 0.215 & 0.411 & 0 & 1 & 1865 \\
\hline edu4 & 0.137 & 0.344 & 0 & 1 & 1865 \\
\hline edu5 & 0.073 & 0.261 & 0 & 1 & 1865 \\
\hline sexo & 0.508 & 0.500 & 0 & 1 & 1865 \\
\hline jefe & 0.380 & 0.486 & 0 & 1 & 1865 \\
\hline ecivil & 0.400 & 0.490 & 0 & 1 & 1400 \\
\hline zona & 0.464 & 0.499 & 0 & 1 & 1865 \\
\hline pos1 & 0.485 & 0.500 & 0 & 1 & 1862 \\
\hline pos2 & 0.360 & 0.480 & 0 & 1 & 1862 \\
\hline pos3 & 0.114 & 0.318 & 0 & 1 & 1862 \\
\hline pos 4 & 0.041 & 0.198 & 0 & 1 & 1862 \\
\hline rama1 & 0.112 & 0.315 & 0 & 1 & 1862 \\
\hline rama2 & 0.056 & 0.231 & 0 & 1 & 1862 \\
\hline rama3 & 0.201 & 0.401 & 0 & 1 & 1862 \\
\hline rama4 & 0.018 & 0.132 & 0 & 1 & 1862 \\
\hline rama5 & 0.243 & 0.429 & 0 & 1 & 1862 \\
\hline rama6 & 0.369 & 0.483 & 0 & 1 & 1862 \\
\hline size & 0.464 & 0.499 & 0 & 1 & 1865 \\
\hline niños & 0.609 & 0.488 & 0 & 1 & 1865 \\
\hline casa & 0.810 & 0.392 & 0 & 1 & 1854 \\
\hline depratio & 1.616 & 1.670 & 0 & 10 & 1852 \\
\hline tel & 0.513 & 0.500 & 0 & 1 & 1865 \\
\hline truck & 0.199 & 0.400 & 0 & 1 & 1865 \\
\hline tarj & 0.141 & 0.348 & 0 & 1 & 1865 \\
\hline refri & 0.731 & 0.443 & 0 & 1 & 1865 \\
\hline lava & 0.566 & 0.496 & 0 & 1 & 1865 \\
\hline Oportun. & 0.137 & 0.344 & 0 & 1 & 1865 \\
\hline Procampo & 0.056 & 0.230 & 0 & 1 & 1865 \\
\hline
\end{tabular}

* Las variables que no suman 1 (100\%) se refieren por diferencia a los No Especificados en la encuesta, quedando agrupados fuera del sector considerado.

Fuente: Elaboración propia con base en la ENIGH, 2005. 
LUIS HuESCA REYNOSO/ANÁLISIS REGIONAL DE LAS REMESAS

Cuadro A4. La participación de las regiones, ENIGH, 2000 y 2005

\begin{tabular}{lccccc}
\hline Variable & Media & Desv. std. & Mínimo & Máximo & Obs. \\
\hline Año 2000 & & & & & \\
\hline Frontera & 0.142 & 0.349 & 0 & 1 & 625 \\
Norte & 0.284 & 0.451 & 0 & 1 & 625 \\
Centro & 0.422 & 0.494 & 0 & 1 & 625 \\
Capital & 0.035 & 0.184 & 0 & 1 & 625 \\
Sur & 0.089 & 0.283 & 0 & 1 & 625 \\
Yucatán & 0.028 & 0.162 & 0 & 1 & 625 \\
\hline Año 2005 & & & & & \\
\hline Frontera & 0.088 & 0.283 & 0 & 1 & 1865 \\
Norte & 0.194 & 0.396 & 0 & 1 & 1865 \\
Centro & 0.453 & 0.498 & 0 & 1 & 1865 \\
Capital & 0.013 & 0.113 & 0 & 1 & 1865 \\
Sur & 0.199 & 0.399 & 0 & 1 & 1865 \\
Yucatán & 0.053 & 0.224 & 0 & 1 & 1865 \\
\hline
\end{tabular}

Fuente: Elaboración propia con base en Hanson (2004) y la ENIGH, 2000 y 2005. 
